\title{
YO SOY EN CUANTO SIGO AL ANIMAL. DE LA INDECIDIBILIDAD ONTOLÓGICA HUMANO-ANIMAL EN DERRIDA
}

\author{
ANTONINO FIRENZE \\ Universitat Pompeu Fabra
}

\begin{abstract}
RESUMEN: El propósito de este artículo es reflexionar acerca de la indecidibilidad ontológica que marca la relación entre subjetividad humana y alteridad animal en la obra de Derrida $L$ 'animal que donc je suis (2006). Para ello, en la primera parte del artículo, el análisis se dirige al texto La Pharmacie de Platon (1968) para hallar las premisas teóricas de dicha indecidibilidad ontológica, poniendo el acento en el papel jugado por la metáfora escritural en la deconstrucción de la metafísica fonologocéntrica operada por Derrida en este contexto previo. A continuación, el artículo analiza la aporía conceptual oculta tras el sintagma L'animal que donc je suis que da título a esta obra póstuma, haciendo especialmente hincapié en la constitutiva indecidibilidad semántica del «je suis».
\end{abstract}

PALABRAS CLAVE: Derrida; animalidad; ontología; fonologocentrismo; deconstrucción.

\section{I am inasmuch as I follow the animal. On the human-animal ontological undecidability in Derrida}

ABSTRACT: The aim of this paper is to venture into the ontological undecidability that characterizes the connection between human subjectivity and animal otherness in Derrida's work L'animal que donc je suis (2006). For that purpose, the paper firstly focuses on the text La Pharmacie de Platon in order to retrace the theoretical premises of this undecidability, highlighting the role played by the scriptural metaphor in the deconstruction of phonologocentric metaphysics carried out by Derrida in this earlier context. Secondly, the paper analyzes the conceptual aporia hidden behind the syntagma L'animal que donc je suis, that enables this posthumous book, namely, to stress the structural semantic undecidability of the «je suis».

KEY WORDS: Derrida; animality; ontology; phonologocentrism; deconstruction.

\section{HaCia Otra AUTOBIOGRAFÍA ANIMAL}

El texto L'animal que donc je suis, publicado póstumamente en 2006, es la transcripción de la larga conferencia-seminario que Derrida pronunció en 1997 en el marco de la correspondiente década de los Coloquios de Cericy-la-Salle dedicado a la temática de L'animal autobiographique ${ }^{1}$. Coherentemente con la temática de dicha década, con su conferencia Derrida pretende explícitamente enfrentarse a la que llama la historia autobiográfica del hombre, poniendo en práctica su habitual método deconstructivo. Con esta finalidad, a lo largo del texto el pensador se compromete a cuestionar esta pulsión autobiográfica, a

1 El título de esa década, que tuvo lugar entre los días 11 y 22 de julio de 1997, fue propuesto por el propio Derrida. Al respecto cfr. el Prefacio de Mallet, J.-L., a DerRida, J., L'animal que donc je suis, texte établi par M.-L. Mallet, Galilée, Paris 2006; trad. cast. de C. de Peretti y C. Rodríguez Marciel, El animal que luego estoy si(gui)endo, Trotta, Madrid 2008, p. 9 . 
su entender característica del pensamiento occidental, por haberse servido del animal con la exclusiva finalidad de poder circunscribir y definir «los propios» del hombre'2.

Como él mismo señala en un pasaje harto sugerente al respecto, para focalizar el blanco de la labor deconstructiva hay que dirigirse precisamente «a esta autodefinición, a esta auto-aprehensión, a esta auto-situación del hombre o del Dasein humano respecto del ser vivo y de la vida animal, a esta auto-biografía del hombre» ${ }^{3}$. Dicho de otro modo, se trata de aclarar explícitamente que «el límite entre el Hombre con $\mathrm{H}$ mayúscula y el Animal con una A mayúscula» no deja de representar «la tesis del sentido filosófico como sentido común sobre la que está edificada esta relación consigo» del humano. Por lo tanto, el objeto explícito de la deconstrucción derridiana deberá ser «la presentación de sí de la vida humana, la autobiografía de la especie humana, toda la historia de sí que se cuenta el hombre», ya que ésta se fundamenta precisamente sobre esta «tesis de un límite como una ruptura o un abismo entre aquellos que dicen "nosotros, los hombres", "yo, el hombre" y lo que ese hombre de los hombres que dicen "nosotros" denomina el animal o los animales»4.

Pues bien, a mi entender, esta labor de deconstruir lo autobiográfico humano halla su punto de partida en la profunda ambigüedad semántica inscrita en el sintagma que da título a la obra: L'animal que donc je suis, traducido con cierta comprensible dificultad al castellano con El animal que luego estoy si(gui)endo ${ }^{5}$. Tras este título se oculta y se desoculta a la vez, ya que en este desocultamiento consiste justamente la tarea deconstructiva que se asigna aquí Derrida, el problema fundamental de la relación humano-animal.

2 Sobre el tema de la «autobiografía» en Derrida cfr. Pelgrefri, I., «Animale autobiografico. Derrida e la scrittura dell'autos», en Lo Sguardo. Rivista di Filosofia, n. 11, 2013 (I), pp. 229-298, en part. sobre l'autobiografía en L'animal que donc je suis, cfr. pp. 263-277. El remarcable análisis de Pelgreffi pone de relieve el doble movimiento que según Derrida atraviesa la pulsión autobiográfica del humano. Por un lado, en efecto, la autobiografía representaría el relato del sujeto humano comprometido en la labor de construcción de su identidad cerrada y auto-referencial, es decir la autobiografía como medio histórico (e incluso historial en el sentido propio de la compulsión a la repetición) de la edificación de «los propios» del hombre. Pero, por el otro, tal pretensión se revelaría a la mirada deconstructiva suspendida sobre un fondo que no es asimilable reflexivamente por parte de la consciencia que escribe, siendo ésta constitutivamente "escrita» desde el «automatismo» corpóreo-vital y animal del inconsciente pre-subjetivo. Del mismo autor véase más ampliamente: La scrittura dell'autos. Derrida e l'autobiografia, Galaad Edizioni, Giulianova 2015.

3 Cfr. Derrida, J., El animal que luego estoy si(gui)endo, op. cit., p. 40.

4 Cfr. ibid., p. 46.

5 Como recuerda M.-L. Mallet en el ya mencionado prefacio al texto (cfr. DerRIDA, J., El animal que luego estoy si (gui)endo, op. cit., p. 9), fue el propio Derrida quien estableció éste como el título de la conferencia y también del extracto de la misma que publicó en las actas del coloquio con el añadido «à suivre» (continuará), indicando justamente el propósito de publicar la continuación de la misma en otra ocasión. Cfr. DERRIDA, J., L'animal que donc je suis (à suivre), en Mallet, M.-L. (ed.), L'Animal autobiographique. Autour de Jacques Derrida, Galilée, Paris 1999, pp. 251-301. 
La tarea que me propongo con este artículo es precisamente descifrar el significado encubierto de este título. Para ello, habrá que detenerse en un análisis de este sintagma centrando nuestra atención en la ambigüedad semántica de la forma verbal «je suis», la cual en efecto puede indicar la primera persona singular del presente indicativo tanto del verbo être (ser) como del verbo suivre (seguir). Además, dicha ambigüedad tiene que ver con que esta forma verbal je suis (yo soy/sigo) se escribe y se pronuncia del mismo modo. En suma, como se intentará mostrar, la perspectiva ofrecida por Derrida en este contexto defiende que en el enunciado «je suis» el ser está entrelazado íntimamente con el seguir, y que este vínculo inextricable se da justamente gracias a la imposibilidad de distinguir, sobre la base tanto de la escritura como de la voz que la pronuncia, lo que esta palabra verdaderamente quisiera decir.

El hecho de que Derrida otorgue un papel tan central a esta palabra «je suis» tiene un sentido profundísimo y es por ello que valdrá la pena entretenernos detenidamente en su interrogación. A tal fin, puede resultar extremadamente útil retomar un texto fundamental de la producción temprana de Derrida, La farmacia de Platón, ya que nos puede aportar los elementos conceptuales decisivos para comprender lo que está realmente en juego en esta estructural indecidibilidad semántica oculta tras el «je suis».

\section{De LA PHONE A LA GRAMME: LA METÁFORA ESCRITURAL y LA IMPOSIBILIDAD DE LA VERDAD}

Como es conocido, el elemento fonético del logos para Derrida es el elemento clave de la deconstrucción, y esto ya desde algunas de sus primeras obras como La voz y el fenómeno (1967), De la gramatología (1967) o La farmacia de Platón (1968), esencialmente porque el fonologocentrismo representaría a su entender el paradigma del gran autoengaño que habría caracterizado la cultura y la filosofía occidental desde su origen griego ${ }^{6}$. Según esta perspectiva, tal y

6 Cfr. Derrida, J., La voix et le phénomène, PUF, Paris 1967, trad. cast. de F. Peñalver; La voz y el fenómeno, Pre-Textos, Valencia 1985; De la grammatologie, Minuit, Paris, 1967; trad. cast. de O. Del Barco, C. Ceretti, De la Gramatología, Siglo XXI, México D.F., 1971; La pharmacie de Platon, en Id., La dissémination, Seuil, Paris, 1972 (se trata de una versión ligeramente ampliada, por la añadidura de la nota 51, respecto a la originaria aparecida en 1968 en la revista Tel Quel, n. 32, pp. 3-48 y n. 33, pp. 18-59); trad. cast. de J. M. Arancibia, La diseminación, Editorial Fundamentos, Madrid, 2007 (1975), pp. 91-260. Sobre la crítica deconstructiva del fonologocentrismo, temática central de la primera filosofía de Derrida, la literatura es vastísima. Me limito a señalar algunas contribuciones introductorias: NoRRIs, C., Deconstruction: Theory and Practice, Routledge, London-New York, 2002 (1982); Culler, J., On Deconstruction, Cornell University Press, Ithaca-New York, 1982; trad. cast. de J. I. Luca de Tena, Sobre la deconstrucción. Teoría y crítica después del estructuralismo, Cátedra, Madrid, 1998; Peretti, C. de, Jacques Derrida. Texto y deconstrucción, Anthropos, Barcelona, 1989; FeRRARIS, M., «Derrida e l'ontologia della scrittura», en Id., Differenze. La filosofía francese dopo lo strutturalismo, Albo Versorio, Milano, 2007, pp. 33-70. 
como se puede apreciar sobre todo en La farmacia de Platón, desde Platón en adelante la escritura (gramme) no habría dejado de ser concebida por nuestra tradición metafísica en tanto que copia-simulacro de la voz (phone), la cual encarnaría la auténtica presencia a sí mismo del hombre. La palabra en cuanto phone sería, en efecto, el emblema de esta presencia viviente del hombre consigo mismo, ya que ésta emergería precisamente del hablarse a sí mismo que sólo se da en la intimidad de la consciencia ${ }^{7}$.

No obstante, cabría subrayar enseguida que, para Platón, esta voz no se debe confundir con el sustrato material del lenguaje en tanto que anclado a los signos, y cuya función esencial sería meramente comunicativa. Más bien, se trata aquí de una voz purificada de todo signo y de toda materialidad, es decir esa voz que en su expresividad pura coincidiría íntimamente con la transparencia de la consciencia interior. Bajo esta premisa, la voz vendría a instituir la consciencia de sí que, en su pureza inmaterial, sería lo más próximo al logos divino en cuanto origen del sentido ${ }^{8}$. Por esta razón, platónicamente la voz interior sería lo que acaba permitiendo el vínculo del logos humano con el logos de la realidad eidética originaria. Frente a la phone entendida como copia viviente del eidos procedente del logos divino, la palabra escrita (gramme) vendría a ser una copia-simulacro o una copia de la copia.

Como recuerda Derrida con su gesto deconstructivo, lo que le interesa realmente a Platón no es llevar a cabo una condena sin fisuras de la gramme en tanto que tal, sino diferenciar entre una gramme mala y una gramme buena. En este sentido, la primera sería tal al ser incapaz de reflejar la pureza eidética del logos preservada por la phone (pecado original que Platón le imputaba a la escritura pseudo-filosófica de los sofistas en tanto que limitada a la materialidad de la palabra-signo e incapaz por ello de aprehender lo inmaterial propio de lo eidético). La segunda, en cambio, sería tal en la medida en que lograría transcribir fielmente la phone interior (es decir, en tanto que escritura dialéctica ontológicamente superior por estar más próxima al eidos del logos divino). Leamos pues lo que escribe el propio Derrida a este propósito en una página de La farmacia de Platón:

«Según un esquema que dominará toda la filosofía occidental, toda una buena escritura (natural, viva, sabia, inteligible, interior, hablante) se opone a una mala escritura (artificiosa, moribunda, ignorante, sensible, exterior,

7 Una reflexión profundamente afín a la articulada en La farmacia de Platón, sobre la que me detendré a continuación, es la que Derrida había llevado a cabo poco antes a propósito del husserliano presente viviente (lebendige Gegenwart) en el ya mencionado texto La voz y el fenómeno, op. cit., cfr. en part. el capítulo III, «El querer-decir como soliloquio», pp. 77-94.

8 A este respecto véase también lo que sostuvo nuestro autor en De la Gramatología, op. cit., p. 17: «Ahora bien, en este logos el vínculo originario y esencial con la phone nunca fue roto. Sería fácil demostrarlo y más adelante intentaremos precisarlo. Tal como se la ha determinado más o menos implícitamente, la esencia de la phone sería inmediatamente próxima de lo que en el "pensamiento" como logos tiene relación con el "sentido", lo produce, lo recibe, lo dice, lo "recoge"». 
muda). Y la buena no puede ser designada más que en la metáfora de la mala. La metaforicidad es la lógica de la contaminación y la contaminación de la lógica (...). Y si la red de las oposiciones de predicados que relacionan una escritura con la otra tiene en su malla a todas las oposiciones conceptuales del "platonismo" — considerado aquí como la estructura dominante de la metafísica- se podrá decir que la filosofía se ha jugado en el juego de esas dos escrituras. Aun cuando no quería distinguir más que entre habla y escritura. Se confirma a continuación que la conclusión del Fedro es menos una condena de la escritura en nombre de la palabra presente que la preferencia de una escritura a otra, de una huella fecunda a una huella estéril, de una simiente generadora, porque depositada en el interior, a una simiente desperdigada en el exterior en pura pérdida: a riesgo de la diseminación» ${ }^{9}$.

Pues bien, como indica Derrida en este fragmento, la disputa platónica entre una gramme buena y viva, que es tal porque fecunda y rebosante de sentido inteligible e interior al alma, y una gramme mala y moribunda, que es tal porque atrofiada en la insignificancia de un sentido diseminado en la exterioridad sensible, se jugaría precisamente en el espacio de una metaforicidad altamente contaminante con respecto a la pretendida pureza del logos. En efecto, la cuestión central que Derrida está aquí circunscribiendo tiene que ver con el papel ambiguo que en el Fedro el propio Platón le otorga al verbo graphein en el marco de la «escena de familia» entre el padre logos y sus dos hijos: el legítimo, phone, y el ilegítimo, gramme ${ }^{10}$. Leamos el fragmento del texto platónico al que Derrida nos remite en estas páginas para describir tal escena de familia.

«Sóc. - Porque es que es impresionante, Fedro, lo que pasa con la escritura, y por lo que tanto se parece a la pintura. En efecto, sus vástagos están ante nosotros como si tuvieran vida; pero, si se les pregunta algo, responden con el más altivo de los silencios. Lo mismo pasa con las palabras. (...) Y si son maltratadas o vituperadas injustamente, necesitan siempre la ayuda del padre, ya que ellas solas no son capaces de defenderse ni de ayudarse a sí mismas. Fed. - Muy exacto es todo lo que has dicho. Sóc. - Entonces. ¿Qué? ¿Podemos dirigir los ojos hacia otro tipo de discurso, hermano legítimo de éste, y ver cómo nace y cuánto mejor y más fuertemente se desarrolla? FED. - ¿A cuál te refieres y cómo dices que nace? Sóc. - Me refiero a aquel que se escribe (graphetai)

9 Derrida, J., La farmacia de Platón, op. cit., cfr. en part. pp. 226-227. Sobre los problemas interpretativos de este texto derridiano se puede consultar con provecho el excelente estudio introductorio a la edición italiana del mismo: Petrosino, S., «Ancora su il pharmakon di Derrida», en Derrida, J., La farmacia di Platone, Jaca Book, Milano, 2015 (1985), pp. 7-47; véanse también: Brogan, W., "Plato's Pharmakon: between two repetitions», en Silverman, J., Derrida and Deconstruction, Routledge, London New York, 1989, pp. 7-23; Di MarTino, C., "Voce, parola, coscienza: Derrida e la genealogía», en Fenomenologia e Società, XXII, n. 2, 1999, pp. 34-74. Más en general sobre el papel de la escritura en Platón véanse: VegETTI, M., "Nell'ombra di Theut. Dinamiche della scrittura in Platone», en Detienne, M. (ed.), Sapere e scrittura in Grecia, Laterza, Roma-Bari, 1989, pp. 201-227; Trabattoni, F., Scrivere nell'anima. Verità, persuasione e dialettica in Platone, La Nuova Italia, Firenze, 1994.

10 Cfr. el capítulo «La herencia del fármacon: la escena de familia», en DerRIDA, J., La farmacia de Platón, op. cit., pp. 216-236. 
con ciencia en el alma del que aprende; capaz de defenderse a sí mismo y sabiendo con quiénes hablar y ante quiénes callarse. FED. - ¿Te refieres a ese discurso lleno de vida y de alma, que tiene el que sabe, del que el escrito se podría justamente decir que es el reflejo? Sóc. - Sin duda» ${ }^{11}$.

Por lo tanto, según Platón, frente a una palabra ilegítima, la escrita (gram$m e)$, incapaz de significar y enseñar algo científicamente verdadero, existe un tipo de palabra legítima, la palabra viviente en la voz (phone), que es tal en la medida en que se «inscribe» (graphetai) en el alma de una manera espontánea, tal y como el hijo legítimo obedece de modo espontáneo a la voz del padre ${ }^{12}$. Mas el asunto central del argumento platónico aquí esgrimido, según Derrida, es que para que pueda darse una experiencia cognoscitiva adecuada y propiamente filosófica, es decir dialéctica, del padre logos, la labor del hijo legítimo phone solo se puede entender a partir de una metáfora que la ata al hacer propio del hijo ilegitimo gramme, es decir a la inscripción material del signo escrito.

En principio, coherentemente con las premisas ontológico-epistemológicas de la filosofía platónica, el logos padre, en cuanto fundamento ontológico del ser inteligible, no se podría aprehender de modo directo desde el ámbito empírico-sensible propio del devenir en el que el ser de la vida y el no-ser de la muerte se hallan íntimamente implicados, y en el que se hallaría atrapada también la escritura debido a su materialidad. No obstante, como señala aquí Derrida, la palabra viva, en cuanto phone e hijo legítimo, necesita de una estructura de socorro metafórica que le muestre cómo decir el logos paterno. Y la paradoja deconstructiva revelada aquí por Derrida consiste justamente en esto: este modelo de comportamiento solo se lo puede proporcionar la palabra escrita en cuanto gramme. Dicho de otro modo, si el Ser, en el sentido del fundamento ontológico de la realidad, no se puede aprehender de modo directo sino solo indirecto, tal y como indican las conocidas metáforas platónicas del logos divino

11 Fedro, $275 d$ - $276 a$. cfr. también $278 a$ : «Sóc. - Pero el que (...) en cambio cree, efectivamente, que en aquellos [discursos] que sirven de enseñanza, y que se pronuncian para aprender — escritos (curs. mia), realmente, en el alma-y que, además, tratan de cosas justas, bellas y buenas, quien cree, digo, que en estos solos hay realidad, perfección y algo digno de esfuerzo y que a tales discursos se les debe dar nombre como si fueran legítimos hijos -en primer lugar el que lleva dentro de él y que está como originado por él, después, todos los hijos o hermanos de éste que, al mismo tiempo, han enraizado según sus merecimientos en las almas de otros-, dejando que los demás discursos se vayan enhorabuena: un hombre así, Fedro, es tal cual, probablemente, yo y tú desearíamos que tú y yo llegáramos a ser». Cfr. Platón, Diálogos, v. III, Fedón, Banquete, Fedro, traducciones, introducciones y notas de C. García Gual, M. Martínez Hernández, E. Lledó Íñigo, Gredos, Madrid, 1986.

12 Como recuerda aquí Derrida (La farmacia de Platón, op. cit., p. 225) a propósito del Sócrates de la Apología, el logos divino se hace presente al logos humano en la medida en que, como el padre, se deja oír por el hijo en el interior del alma en cuanto voz de la conciencia. Cfr. Apología, 31 c: «Hay junto a mi algo divino y demónico; (...) Está conmigo desde niño, toma forma de voz (phone) y, cuando se manifiesta, siempre me disuade de lo que voy a hacer, jamás me incita». Véase Platón, Diálogos, v. I, Apología, Critón, Eutifrón, Ion, Lisis, Cármides, Hípias Menor, Hipias Mayor, Laques, Protágoras, Introducción general de E. Lledó Íñigo, traducción y notas de J. Calonge Ruiz, E. Lledó Íñigo, C. García Gual, Gredos, Madrid, 1981. 
en cuanto sol-bien-padre que se halla epekeina tes ousias, es decir «más allá de la esencia» ${ }^{13}$, entonces se hace inevitable que el discurso propiamente filosófico en cuanto logos tes ousias acabe contaminándose metafóricamente con la materialidad del signo.

«La invisibilidad absoluta del origen de lo visible, del bien-sol-padre-capital, la sustracción a la forma de la presencia o de la entidad, todos esos excesos que Platón designa como epekeina tes ousias (más allá de la entidad o de la presencia) da lugar, si se puede decir aún, a una estructura de suplencia tal que todas las presencias serán los suplementos sustituidos al origen ausente y que todas las diferencias serán, en el sistema de las presencias, el efecto irreductible de lo que queda epekeina tes ousias. (...) El retiro del rostro abre y limita a la vez el ejercicio de la dialéctica. La suelda irremediablemente a sus "inferiores", las artes miméticas, el juego, la gramática, la escritura, etc. La desaparición del rostro es el movimiento de la différance que inaugura violentamente la escritura y que se abre a la escritura ${ }^{14}$.

En suma, según el Derrida lector de Platón, es la escritura lo que hace posible la articulación del discurso-logos sobre las esencias, con la subsiguiente explicitación de la dynamis dialéctica en su función de diferenciación de lo que es plenamente respecto a lo que es y no es a la vez, es decir de la presencia eidética frente a los ente captados en el ámbito de la dimensión empírico-sensible característica del devenir fenoménico. El signo escrito, gramme, viene a realizar una función esencial en tanto que "suplemento» del fundamento ausente, de un origen que solo se da en el diferimiento escritural de su pensabilidaddecibilidad dialéctica.

La principal consecuencia teórica de tal deconstrucción del texto platónico resulta ser, por lo tanto, altamente paradójica: la escritura es el lugar material en el que se hace visible «inscribiéndose» metafóricamente lo inmaterial de la dimensión eidética. $\mathrm{O}$, lo que viene a ser lo mismo, ésta no es decible dialécticamente, ni pensable filosóficamente, sin la contaminación de su inmaterialidad y pureza inteligible con la materialidad del signo escrito. En este sentido, el gesto de Platón no consistiría tanto en plantear una simplista dicotomía entre phone y gramme, sino en pretender borrar esta filiación peligrosísima que se viene a entablar entre padre e hijo legítimo gracias a la mediación entre los dos llevada a cabo por el hijo ilegítimo. Mediación que, precisamente, Platón

13 Cfr. República, 509 b: "y así dirás que a las cosas cognoscibles les viene del Bien no sólo el ser conocidas, sino también de él les llega el existir y la esencia, aunque el Bien no sea esencia, sino algo que se eleva más allá de la esencia en cuanto a dignidad y a potencia». Véase Platón, Diálogos, v. IV, República, Introducción, traducción y notas de C. Eggers Lan, Gredos, Madrid, 1988. Para un análisis detallado de esta temática central de la República, véase: Vegetti, M., "L’idea del bene nella "Repubblica” di Platone», en Discipline filosofiche, n. 1, 1993, pp. 207-229; SzlezÁK, T. A., "L'idée du Bien en tant qu'archê dans la "République” de Platon", en FAtTal, M. (ed.), La philosophie de Platon, L'Harmattan, Paris, 2001, pp. 345-372.

14 Derrida, J., La farmacia de Platón, op. cit., p. 254-255 (trad. ligeramente modificada). Distanciándome de la solución adoptada por el traductor del texto derridiano, quien lo traduce con «diferenzia», prefiero mantener el término différance sin traducirlo. 
pretende borrar y ocultar después de haber recurrido a ella, si bien «metafóricamente», para poder hallar el camino legítimo hacia la verdad del Ser.

Ahora bien, como acabamos de ver, estas consideraciones nos llevan al concepto de différance, entendida aquí como origen impresentable del rostro del padre logos, porque epekeina tes ousias, y por ello no aprehensible de modo directo por parte de la presencia viviente de la phone. Su presencia imposible se da entonces solo gracias al permanente diferir escritural del sentido y de la verdad del logos en tanto que inscrito en la buena gramme metafóricamente contaminada con la mala gramme. Precisamente esto es lo que debería mostrar, según Derrida, esa «a» que ilegítimamente ocupa el lugar de la «e» en el corazón de la palabra escrita différance ${ }^{15}$. Para Derrida se trata de introducir la escritura como elemento esencial de la diseminación del sentido que contamina de modo constitutivo el fonologocentrismo de la metafísica ${ }^{16}$. Con la diseminación del sentido propia de la escritura, por lo tanto, lo que se muestra no es el Sentido del padre-ser-logos, sino las huellas que la différance produce, pero sin mostrarse a sí misma en una pretendida e ilusoria pureza trascendental. Más bien, se oculta estructuralmente tras estas mismas huellas. La verdad, por lo tanto, no es presentable directamente como ser, esencia o palabra dialéctica, sino solo de modo indirecto a través de las infinitas huellas que la différance produce como efecto de las alteraciones y desplazamientos del sentido que la caracterizan en la escritura, en tanto que escritura ${ }^{17}$. Por todo ello, según Derrida, detrás de la

15 Cfr. Derrida, J., «La différance», en Id., Marges - de la philosophie, Minuit, Paris, 1972; trad. cast. de C. González Marín, Márgenes de la filosofía, Cátedra, Madrid, 1994 (1989), pp. 37-62, en part. p. 40: «Recuerdo, pues, de una manera completamente preliminar, que esta discreta intervención gráfica, que no se ha hecho en principio ni simplemente por el escándalo del lector o del gramático, ha sido calculada en el proceso escrito de una interrogación sobre la escritura. Ahora bien, se da el caso, diría en realidad, de que esta diferencia gráfica (la $a$ en lugar de la $e$ ), esta diferencia señalada entre dos notaciones aparentemente vocales, entre dos vocales, es puramente gráfica; se escribe o se lee, pero no se oye (ne s'entend pas). No se puede oír (entendre), y veremos también en qué sentido sobrepasa el orden del entendimiento (entendement)». Como es conocido, con el concepto de différance Derrida indica precisamente el elemento «casi-trascendental» que en su filosofía viene a ocupar el lugar, empero sin sustituirlo sino más bien desplazándolo reiteradamente mediante la práctica escritural deconstructiva, del fundamento ausente que ha actuado tras las líneas de todo discurso metafísico. La literatura crítica sobre este aspecto es vastísima, me limito por lo tanto a señalar el esclarecedor estudio introductorio de Vergani, M., Derrida, Mondadori, Milano, 2000, en part. pp. 37-56. Más ampliamente véase Wood, D., Bernasconi, R. (eds.), Derrida and Différance, Northwestern University Press, Evanston, 1988.

16 A este respecto, resulta clarificador lo que escribe un reputado intérprete como Mario Vergani: «La différance si riferisce a un significato passando anche attraverso la grafia. Il significato qui necesita della gramme oltre che della phone, senza che si dia un primum. La différance dunque contesta, ma non rovescia semplicemente la gerarchia fonologocentrica». Cfr. Vergani, M., Derrida, op. cit., p. 38.

17 Respecto al concepto de «huella», que traduce el francés «trace» del texto derridiano, véase DALMASSo, G., "Impensabilità della scrittura», estudio introductorio a la edición italiana de Derrida, J., Della grammatologia, Jaca Book, Milano, 1998 (1969), pp. I-VIII, en part. p. IV: «Il termine traccia [huella] è l'altro termine decisivo che fa coppia con scrittura. Traccia 
phone no se puede hallar una verdad transparente y plena, sino más bien una verdad imposible o, mejor dicho, la imposibilidad de la verdad.

Finalmente, es gracias a la labor de diferimiento permanente del sentido que la différance produce en el corazón del logos que, según Derrida, se revela el carácter indecidible de la escritura como pharmakon, es decir a la vez veneno y remedio. Que las dos caras de la escritura como pharmakon sean pensables en los términos de unos «indecidibles» es el propio Derrida quien lo afirma en un momento de la larga entrevista publicada pocos años después bajo el título de Posiciones ${ }^{18}$. Los «indecidibles», en efecto, se conciben aquí como unidades conceptuales resultantes paradójicamente de una oposición interna de términos irreductibles a una síntesis dialéctica capaz de conservar el sentido positivo del concepto mediante la supresión de su sentido negativo. El gesto deconstructivo consiste entonces en rechazar la condición metafísica, ontológicamente vinculante, según la cual esta positividad del concepto se alcanzaría sólo mediante la supresión simultánea de lo negativo que implícitamente lo habita.

Con el término de «indecidibles», por lo tanto, nos hallamos frente a la imposibilidad de llevar a cabo esta labor metafísica de purificación interna de la palabra-concepto, ya que lo que a Derrida realmente le interesa es poner de relieve la función profundamente deconstructiva que la contaminación recíproca de los dos lados de estas unidades conceptuales binarias acaba ejerciendo sobre el sistema discursivo de la metafísica. Como señala el propio Derrida, los indecidibles deben ser pensados precisamente como "falsas" propiedades verbales, nominales o semánticas, que ya no se dejan comprender en la oposición filosófica (binaria) y que no obstante la habitan, la resisten, la desorganizan pero sin constituir nunca un tercer término, sin dar lugar nunca a una solución en la forma de la dialéctica especulativa ${ }^{19}$. El significado de una palabra-concepto se revela entonces «indecidible» cuando resulta imposible determinar su auténtico sentido desde el momento en que de éste son posibles múltiples interpretaciones. La indecidibilidad se convierte así en uno de los efectos textuales más determinantes de la práctica deconstructiva derridiana ya que, gracias a la

significa nel percorso derridiano impossibilità del costituirsi della presenza se non in relazione ad una non presenza che insidia originariamente la stessa presenza: impossibilità del costituirsi di un "dentro" se non in relazione ad un "fuori" che già dall'inizio rende possibile la sua costituzione».

18 Cfr. Derrida, J., Positions, Minuit, Paris, 1972; trad. cast. de M. Arranz, Posiciones, Pre-Textos, Valencia, 1977, pp. 49-131. Como es conocido, en tanto que uno de los términos clave de la decostrucción, el concepto de «indecidibles» recorre sin solución de continuidad la extensa obra escrita de Derrida. Sobre este aspecto véanse los siguientes estudios: Petrosino, S., Jacques Derrida e la legge del possibile, Guida, Napoli, 1983, pp. 99-128; Vergani, M., Derrida, op. cit., pp. 74-95; Id., Dell'aporia. Saggio su Derrida, Il Poligrafo, Padova, 2002, pp. 251-278. Para una lista de los principales «indecidibles» (tales como pharmakon, différance, suplemento, huella-gramme, diseminación, etc.) de los que Derrida se ha servido en sus textos, véase la nota de Finas, L., "Indecidibles», en VV.AA., Écarts : quatre essais à propos de Jacques Derrida, Fayard, Paris, 1973, pp. 321-322.

19 Cfr. Derrida, J., Posiciones, op. cit., en part. p. 56. 
polisemia de sus términos clave, Derrida puede invalidar y destruir el sentido único que los conceptos filosóficos tradicionales pretenden afirmar. Como ha sido oportunamente señalado, los numerosos enunciados indecidibles que recorren la obra de Derrida, se hacen justamente eco de una «indecidibilidad de hecho» en tanto que "resistencia de hecho a la razón», que acaba revelando el fracaso de toda pregunta por un sentido «"verdadero", "único", "serio", "autentico"» propia de los conceptos filosóficos ${ }^{20}$.

Por lo tanto, si la escritura buena puede ser pharmakon en el sentido de remedio, habrá que desocultar su huella oculta implícitamente en la indecidibilidad del propio término pharmakon, el cual, en efecto, significa sí remedio, pero también veneno. La buena gramme, que es buena porque es escritura dialéctica entendida como remedio frente a la distancia ontológica entre el eidos y su copia originaria encarnada por la intimidad de la phone, se halla arrastrada por la mala gramme, es decir por el veneno que emponzoña la decidibilidad del sentido y de la verdad. Entonces no es posible resolver la rivalidad que platónicamente enfrenta lo fonético y lo escrito otorgándole un valor superior a la escritura dialéctica en tanto que transcripción fiel de la phone originaria. Y esto porque para Derrida no hay una verdad del logos que se oculta detrás de la voz y que esta voz tendría que poder decir a la vez que se dice a sí misma. Justamente, según Derrida, lo que en realidad se halla en la escritura es el elemento de la «verdad» del yo en cuanto verdad siempre falta de sí misma, tal y como la noción de différance viene a indicar de modo irrevocable.

\section{JE SUIS: O DE LA INDECIDIBILIDAD ENTRE SER Y SEGUIR}

Volviendo ahora a nuestro texto, y al problema oculto tras el sintagma que da título al mismo, desde la perspectiva deconstructiva aquí ganada, lo escritogramme «Je suis» no viene a resolver el problema de la indistinción fonética de la palabra pronunciada, sino que se limita a subrayar la indecidibilidad de su sentido o verdad y a ponerla radicalmente en evidencia. A mi entender, entonces, los dos sentidos, "yo soy»/«yo sigo», ocultos tras el enunciado "je suis», deberían concebirse en tanto que «indecidibles». Que Derrida escriba «je suis» para indicar tanto "yo soy» como "yo sigo» implica la imposibilidad de escoger entre el ser y el seguir, ya que el ser del yo no puede no ser pensado a partir de esta contaminación e implicación constitutiva con el seguir. ¿Quién soy yo?/¿A quién sigo yo? se pregunta Derrida al mismo tiempo. Lo que vendría a decir que para que el yo sea tiene que seguir, ya que el «ser» de este yo está íntimamente contaminado, de manera constitutiva, con el «seguir».

Ahora bien, como el propio Derrida indica, el sintagma L'animal que donc je suis nos lleva inmediatamente a Descartes y a su cogito ergo sum, ocupando

20 Cfr. Ramond, C., Vocabulaire de Derrida, Ellipses, Paris, 2001, pp. 43-47, en part. p. 44. 
aquí el donc el lugar del cartesiano ergo ${ }^{21}$. La alteración del significado del sintagma cartesiano no podría ser más radical teniendo en cuenta además la sintomática "pasión» por el animal-máquina que caracteriza los textos de Descartes sobre los animales.

«No llamaría en primer lugar a seguir o proseguir, ni siquiera a citar, para celebrarlo, el ergo sum, el "luego existo" de alguien que, desde el Discurso del método hasta las Meditaciones, abrió sin duda el camino de la narración autobiografilosófica, el de la presentación de sí mismo como presentación de la filosofía, el de alguien igualmente que dudó hasta la hipérbole pero jamás tuvo ninguna duda (...) de que el animal no fuese más que una máquina, llegando incluso a convertir dicha indubitabilidad en una especie de condición de la duda, del ego como tal, como ego dubito, como ego cogito y, por lo tanto, como ego sum. La relación consigo misma del alma y del pensamiento, el ser mismo de la sustancia pensante implicaba ahí el concepto de un animalmáquina privado de lo que, en resumidas cuentas, sería nada menos que el ego como ego cogito, "yo pienso".» 22

Por lo tanto, la evidencia apodíctica de que yo soy en cuanto pienso se ve alterada desde su espacio interior más íntimo por su doble oculto encarnado por la animalidad. Según Derrida, en efecto, la indubitabilidad del «cogito ergo sum» no depende tanto de la evidencia apodíctica entrañada por el cogito en la transparencia auto-referencial de su actividad pensante. Más bien, se debe desvelar la auténtica condición trascendental que hace posible dicha prerrogativa ontológica, que consiste justamente en la reducción mecanicista del animal a mera res extensa. Por el contrario, en el sintagma derridiano, el lugar del cogito debe ser ocupado ahora por el animal, de modo que éste podría leerse del siguiente modo: «el animal que luego yo soy/sigo». No obstante, es importante subrayar que con este sintagma Derrida no pretende proporcionar una nueva definición de la esencia o naturaleza humana. Por el contrario, lo que quiere es deconstruir toda posibilidad de una definición metafísica de lo humano, la cual para ser tal debería fundamentarse precisamente sobre la univocidad del término «ser». Frente a tal pretensión metafísica, nuestro pensador opta por contaminar el significado de «ser», o, lo que vendría a ser lo mismo, el esse del sum, mediante su imbricación íntima e indecidible con el «seguir» al animal. En suma, el sintagma derridiano L'animal que donc je suis deconstruye el sintagma cartesiano cogito ergo sum, reconduciéndolo justamente a su fondo impensado en tanto que animal.

Por eso, tal sintagma se podría provisionalmente reformular, en sentido anticartesiano, del siguiente modo: el animal que yo soy en cuanto sigo al animal. Empero, ¿para qué seguir al otro animal, es decir al animal no humano? ¿Qué significa exactamente este seguir? ¿Cómo entender más concretamente este

21 Derrida, J., El animal que luego estoy si(gui)endo, op. cit., p. 94. Aquí se lee que aquello en lo que Derrida piensa al «insertar ese «luego» en medio del animal que estoy si(gui)endo» es justamente el ergo cartesiano.

22 Ibid. 
«seguir» que viene a desarticular desde su más íntima sustancia ontológica el «ser» del yo humano en cuanto ser pensante? ¿Qué significa, como escribe Derrida, «seguir e ir tras» el animal? ¿Se puede «responder de lo que quiere decir «yo estoy si(gui)endo» (je suis) cuando eso parece regir un «estoy si(gui) endo en cuanto estoy si(gui)endo tras el animal» (je suis en tant que je suis après l'animal), o "soy en cuanto estoy cerca del animal» (je suis en tant que je suis auprès de l'animal)»? ${ }^{23}$.

Sigamos pues los pasos que emprende Derrida para dar con una «respuesta» a estas preguntas fundamentales. Para ello, es importante recordar que el texto que estamos analizando halla su momento álgido en la descripción de la experiencia inquietante vivida por Derrida al verse visto desnudo por su gato en el lavabo y, de repente, verse expuesto a la incómoda mirada que éste le dirige. Tal incomodidad inquietante desatada por la mirada animal, como vamos a ver a continuación, nos remite al problema de la mirada animal en tanto que mirada que lo absolutamente otro le puede dirigir al sujeto humano. Pues bien, ¿cómo entender este «seguir e ir tras el animal» que está en juego al verse visto desnudo frente a la mirada animal?

"¿ir-tras-él en el sentido de la caza, del adiestramiento, de la domesticación o ir-tras-él en el sentido de la sucesión y de la herencia? En todos los casos, si voy tras él, el animal viene por lo tanto antes que yo, más pronto que yo (...). El animal está ahí antes que yo, ahí a mi lado, ahí delante de mí — de mí, que estoy si(gui)endo tras él-. Y así pues, también, puesto que está antes que yo, helo aquí detrás de mí. Me rodea. Y desde este ser-ahí-delante-de-mí se puede dejar mirar, sin duda, pero - la filosofía lo olvida quizás, ella sería incluso este olvido calculado- él también puede mirarme. Tiene su punto de vista sobre mí. El punto de vista del otro absoluto y esta alteridad absoluta del vecino o del prójimo nunca me habrá dado tanto que pensar como en los momentos en que me veo desnudo bajo la mirada de un gato» ${ }^{24}$.

De entrada, por lo tanto, este «seguir» parecería poderse entender en el sentido del «ir tras» o «venir después», tal y como plantea en estas páginas Derrida retomando el Génesis bíblico. Más concretamente, el pensador se refiere al que se conoce generalmente como el segundo relato del Génesis (Bereshit) en el

23 Derrida, J., El animal que luego estoy si(gui)endo, op. cit., p. 25.

${ }^{24}$ Ibid., p. 26. Es evidente que aquí «el prójimo» o «el vecino» remiten críticamente al pensamiento de la alteridad de Lévinas. Éste, en efecto, es considerado por Derrida incapaz de concebir lo absolutamente otro en tanto que otro no-humano. La crítica al antropocentrismo latente en la filosofía de Lévinas encuentra en este texto un desarrollo específico: cfr. ibid., pp. 127-141. Debido a los límites de este trabajo nos es imposible tratar adecuadamente esta cuestión. Más en general, sobre la interpretación derridiana de la filosofía de Lévinas, véanse: Bernasconi, R., «The Trace of Levinas in Derrida», en Wood, D., Bernasconi, R. (eds.), Derrida and Différance, op. cit., pp. 13-29; Wyschogrod, E., «Derrida, Levinas and violence», en Silverman, H. J., Derrida and Deconstruction, Routledge, London-New York, 1989, pp. 177194; Critchley, S., The Ethics of Deconstruction. Derrida and Levinas, Edinburgh University Press, Edimburgh, 1999; Petrosino, S., La scena umana. Grazie a Derrida e Lévinas, Jaca Book, Milano, 2010. 
que Dios pone al mundo el hombre (Ish) solo y antes de la mujer (Isha), pero después de haber creado a los animales. Aquí Dios le encomienda al hombre dar nombre a los animales, a diferencia del primer relato del Génesis en el que Dios crea el hombre y la mujer a la vez y les manda someter a los animales. Pues bien, el asunto central con respecto a las Escrituras es que según éstas el hombre viene después de los animales, «sigue» a la venida de los animales en la tierra, por lo que de entrada habría una posterioridad temporal del hombre frente al animal. Sin embargo, como indica nuestro filósofo, este «seguir» podría declinarse también en el sentido del «ir tras», es decir en el sentido del perseguir típico del cazador o domesticador que, siempre según el relato bíblico, por mandato divino va tras el animal desde el origen del tiempo para someterle. Mas la labor deconstructiva pretende justamente desocultar el sentido de este «seguir» en cuanto ir tras y perseguir al animal propio del hombre. Para ello, Derrida defiende que en el fondo el hombre sigue y va tras el animal, y es en este seguir e ir tras el animal que el yo humano «ergo» es, no tanto para cazarlo o domesticarlo sino más radicalmente, para nombrarlo. Y al nombrarlo poderse nombrar a sí mismo en tanto que poseedor exclusivo de este poder de dar nombre ${ }^{25}$.

Derrida quiere así poner de relieve la prioridad del nombrar respecto al someter-domesticar, ya que en cuanto prerrogativa antropo-teomórfica el nombrar se entiende como la forma primordial de la dominación humana sobre los

25 Tal nombrar, asimismo, vendría a confirmar la mortalidad de los animales, cuyo nombre, en la medida en que justamente debería sobrevivirles, anunciaría sin ambages su fin inevitable. Cfr. DERrida, J., El animal que luego estoy si(gui)endo, op. cit., p. 36.: "pues se trata -me parece-, como en toda denominación, del anuncio de una muerte por venir según la supervivencia del espectro, la longevidad del nombre que sobrevive al portador del nombre. Aquel que recibe un nombre se siente mortal o moribundo precisamente porque el nombre querría salvarlo, llamarlo y asegurar su supervivencia. Ser llamado, oírse nombrar, recibir un nombre por vez primera es quizá saberse mortal e incluso sentirse morir. Ya muerto por estar prometido a la muerte: moribundo. (¿Cómo se podría — planteo la cuestión de pasadanegarle entonces al animal, así privado de la denominación, el acceso a la experiencia de la muerte como tal?)» Se hace aquí patente la referencia crítica a la concepción heideggeriana de la muerte como prerrogativa ontológico-existencial exclusiva del hombre. Cfr. HEIDEgGer, M., Die Grundbegriffe der Metaphysik. Welt - Endlichkeit - Einsamkeit, Vittorio Klostermann Verlag, Frankfurt a.M., 1983; trad. cast. de A. Ciria, Los conceptos fundamentales de la metafísica. Mundo - finitud - soledad, Alianza, Madrid, 2007, en part., pp. 321-322: "Cuestionable es si la muerte es lo mismo en el caso del animal y en el caso del hombre, aunque puedan constatarse coincidencias físico-químicas y fisiológicas. (...) La muerte del animal ¿es un morir o un acabar? (...) el animal no puede morir, sino sólo acabar, en la medida en que el morir lo atribuimos al hombre». Al margen de las numerosas referencias al pensamiento de Heidegger a lo largo del texto, Derrida le dirige una atención especial en la parte final de su conferencia, cfr. DeRrida, J., El animal que luego estoy si(gui)endo, op. cit., pp. 167-189. Para una reconstrucción de la crítica derridiana a la filosofía de la animalidad de Heidegger véase Fontenay, E. de, Le silence des bêtes. La philosophie à l'épreuve de l'animalité, Fayard, Paris, 1998, pp. 699-704. Sobre los problemas relativos a la filosofía de la animalidad de Heidegger, me permito remitir a FiREnzE, A., "AA dog does not exist but merely lives": The Question of Animality in Heidegger's Philosophy», en Philosophy Today, v. 61, n. 1, 2017, pp. 135-154. 
animales. Por lo tanto, la finalidad deconstructiva que anima estas reflexiones consiste en poner radicalmente en entredicho este poder de nombrar que según nuestra tradición teológico-filosófica le correspondería de modo exclusivo al hombre. A este respecto la reflexión derridiana resulta sumamente interesante por poner el acento en el carácter esencialmente sacrificial de la autobiografía antropo-teomórfica que marca el destino de Occidente, la cual justamente tendría su inicio (y con éste iría incluido el inicio del tiempo y de la historia humana tout court) en el pecado original de dar nombre a los animales ${ }^{26}$.

«Completamente solo, Dios deja a Ish llamar a los otros seres vivos, darles nombres en su nombre, a esos animales más viejos o más jóvenes que él, a esos seres vivos que llegaron al mundo antes que él y que fueron nombrados por él, como dice el segundo relato. En ambos casos, en el doble sentido de la palabra, el hombre va tras el animal. Lo sigue. Este "tras" de la secuencia, de la consecuencia o de la persecución no está en el tiempo, no es temporal: es la génesis misma del tiempo ${ }^{27}$.

Desde esta perspectiva el auténtico autor del pecado original no sería ni la pareja compuesta por el hombre Adán y la mujer Eva, culpables de haber recogido el fruto prohibido; ni, posteriormente, el Caín agricultor fratricida del ganadero Abel, preferido por Dios a su hermano precisamente por su labor de sumisión-sacrificio de los animales ${ }^{28}$. Por el contrario, según Derrida, la culpa originaria sería imputable a la díada antropo-teomórfica Ish-Dios empeñada en definirse a sí misma sobre la base de este poder de nombrar a los animales. Por lo tanto, bajo la mirada deconstructivista aquí defendida «Dios destina a los animales a experimentar el poder del hombre, para ver el poder del hombre en acto», es decir "para ver al hombre tomar el poder sobre todos los demás seres vivos ${ }^{29}$, como si Dios no fuese suficientemente potente y por ello dejara a Ish el

${ }^{26}$ Que el carácter sacrificial de la metafísica fonologocéntrica para Derrida tenga que ir asociado de modo constitutivo a la prerrogativa ontológico-antropocéntrica del poder de nombrar, en cuanto forma primordial de apropiación, asimilación e interiorización de lo otro, se ve confirmado en DERRIDA, J., «"Il faut bien manger" ou le calcul du sujet». Entretien avec Jean-Luc Nancy", en Id., Points de suspension, Galilée, Paris, 1992, pp. 269-301 (originariamente publicado en Cahiers Confrontation, n. 20, 1989, pp. 91-114). Cfr. en part. p. 296: «Si maintenant la limite entre le vivant et le non-vivant paraît aussi peu sûre, du moins comme limite oppositionnelle, que celle de 1'homme' et de 1"animal', et si dans l'expérience (symbolique ou réelle) du 'manger-parler-intérioriser', la frontière éthique ne passe plus rigoureusement entre le 'tu ne tueras point' (l'homme, ton prochain) et le 'tu ne mettras pas à mort le vivant en général', mais entre plusieurs modes, infiniment différents, de la conception-appropriation-assimilation de l'autre, alors, quant au 'Bien' de toutes les morales, la question reviendra à déterminer la meilleure manière, la plus respectueuse et la plus reconnaissante, la plus donnante aussi de se rapporter à l'autre et de rapporter l'autre à soi.»

27 DERRIDA, J., El animal que luego estoy si(gui)endo, op. cit., p. 33.

28 Sobre este aspecto de la cuestión véase: Dalmasso, G., «Nudo im/proprio. Derrida e l'animale», en D'Alessandro, P., Potestio, A., Su Jacques Derrida. Scrittura filosofica e pratica di decostruzione, Edizioni Universitarie di Lettere Economia Diritto, Milano, 2008, pp. 197208, en part. p. 203.

29 Derrida, J., El animal que luego estoy si(gui)endo, op. cit., p. 32. 
poder de decir «"yo nombro", "yo llamo"», para ver de este modo cómo el hombre lo haría ${ }^{30}$. Pues bien, bajo una atenta mirada al texto podemos comprender que este para ver juega aquí un papel decisivo en el discurso deconstructivo derridiano, tan decisivo que podríamos incluso considerarlo como elemento resolutivo de la problemática «vergüenza de tener vergüenza» que Derrida asocia a la experiencia del ser visto desnudo por un gato que, precisamente, ocupa en este texto una enorme relevancia.

«Es como si yo sintiera vergüenza, entonces, desnudo delante del gato, pero también sintiera vergüenza de tener vergüenza. Reflexión de la vergüenza, espejo de una vergüenza vergonzosa de sí misma, de una vergüenza a la vez especular, injustificable e inconfesable. En el centro óptico de una reflexión así se encontraría el asunto; y, según yo lo veo, el foco central de esta experiencia incomparable que denominamos la desnudez. Y de la que se cree que es lo propio del hombre, es decir, ajena a los animales, desnudos como están —se piensa entonces-, sin la menor conciencia de estarlo. ¿Vergüenza de qué y desnudo ante quién? ¿Por qué dejarse invadir por la vergüenza? ¿Y por qué esta vergüenza que se sonroja por sentir vergüenza?» ${ }^{31}$.

Al verse visto desnudo por este gato se descubre totalmente vulnerable frente a esa mirada porque justamente en cuanto cuerpo que vive en la pura inmanencia, sin palabras, se ve desubicado respecto a la pretendida prerrogativa ontológica de nombrar que fundamentaría su humanidad. Es decir, en cuanto cuerpo que no está atravesado por la trascendencia del lenguaje hablante-pensante y por eso se descubre desnudado de su humanidad. Dicho de otro modo, la desnudez vinculada a la ausencia de vestimenta nos introduce de modo impensado en una desnudez mucho más profunda, cual es la desnudez resultante de la ausencia de lenguaje como vía preferencial de la relación de lo humano consigo mismo y con la alteridad ${ }^{32}$. Por consiguiente, si la vergüenza experimentada frente a la mirada del gato puede reconducirse a la desnudez lingüística, la «vergüenza de tener vergüenza», subrayada aquí por nuestro autor, nos reconduce entonces a la deuda inconfesable que despierta en mí la mirada sin fondo de este animal en tanto que radicalmente otro, frente al cual la

$30 \quad$ Cfr. ibid., p. 33.

31 Ibid., p. 18.

32 He desarrollado un análisis específico de esta parte del texto derridiano en otro artículo al que me permito remitir: FIRENZE, A., «¿El cuerpo como frontera? El problema de la limitrofía ontológica humano-animal en L'animal que donc je suis de Derrida», en Philosophical Readings. Online Journal of Philosophy (artículo aceptado, pendiente de publicación). Sobre este aspecto véanse además Cіматті, F., Filosofia dell'animalità, Laterza, Roma-Bari, 2013, pp. 87-105, en part. pp. 89-93; Lawlor, L., This Is Not Sufficient. An Essay on Animality and Human Nature in Derrida, Columbia University Press, New York, 2007, en part. pp. 79-85. Más en general sobre la filosofía de la animalidad de Derrida véanse: CALARCo, M., "The Passion of the Animal: Derrida», en Id., Zoographies. The Question of the Animal from Heidegger to Derrida, Columbia University Press, New York 2008, pp. 103-149; Llored, P., Jacques Derrida. Politique et éthique de l'animalité, Éditions Sils Maria, Paris, 2013. 
humanidad ha pecado, desde el origen del tiempo, cuando al darle, por mandato divino, el nombre «el Animal» se ha nombrado a sí misma «el Hombre».

Este para ver, de hecho, nos conduce hacia ese vértigo que el autor dice experimentar, «desde hace tanto tiempo», cada vez que, atrapado por la mirada de su gato, tiene la tentación de escapar porque incapaz de aguantar el peso de esta mirada, o, mejor dicho, el peso de la culpa que esta mirada sin fondo y sin palabras parece atribuirle en cuanto miembro de la humanidad. Para nuestro autor se trata de poner el acento en este «para ver» de un Dios a la vez «potente y desvalido» que precisamente en ese tiempo antes del tiempo se halla expuesto sin protección «al acontecimiento de lo que iba a ocurrir entre el hombre y el animal». Como sostiene aquí Derrida, es este tiempo antes del tiempo lo que siempre le ha producido vértigo cada vez que se ha visto sorprendido desnudo por la mirada de este gato.

«Me pregunto a menudo si ese vértigo, en relación con el abismo de semejante "para ver" en el fondo de los ojos de Dios, no es el que me atrapa cuando me siento tan desnudo ante un gato, de frente, y cuando, cruzando en ese momento su mirada, oigo al gato o a Dios preguntarse, preguntarme: ¿va a llamar?, ¿va a dirigirse a mí? ¿Cómo va a llamarme, ese hombre desnudo (...)? Hace tanto tiempo. Es como si el gato se acordase, como si él me recordara sin decir palabra el relato terrible del Génesis. ¿Quién nació el primero antes que los nombres? ¿Quién ha visto venir al otro en esos lugares desde hace tanto tiempo? ¿Quién habrá sido el primer ocupante y, por lo tanto, el amo? ¿El sujeto? ¿Quién sigue siendo el déspota desde hace tanto tiempo? » ${ }^{33}$.

Pues bien, la deconstrucción del esquema conceptual antropo-teomórfico aquí articulada por Derrida no podría ser más radical: parece claro por este fragmento que el auténtico «absolutamente otro» frente al cual el humano se debe, es decir, frente al cual está profundamente en deuda por haberle hecho sufrir las consecuencias del acto institutor de su auto-definición ontológica, no es el otro humano, en cuyo rostro desnudo (levisianamente) se mostraría de modo indirecto la trascendencia absoluta de Dios, sino este animal concreto, este gato. No el animal en general, sino, más precisamente, este gato que nos mira y al mirarnos nos empuja a confesar, al margen de toda autobiografía exculpatoria y edificante, el «verdadero» pecado original, el cual es tal justamente en la medida en que da origen al poder de nombrar en el que consiste «lo propio» del hombre.

«Esos tiempos serían también los que separan en principio, y si eso fuera posible, la autobiografía de la confesión. La autobiografía se transforma en confesión cuando el discurso sobre sí no disocia la verdad de la confesión, por lo tanto, de la falta, del mal y de los males y, antes que nada, de una verdad debida, de una deuda, en realidad, que habría que satisfacer. ¿Por qué deberíamos la verdad? ¿Por qué pertenecería a la esencia de la verdad ser debida y estar desnuda? ¿Y, por lo tanto, confesada?» ${ }^{34}$.

33 DERridA, J., El animal que luego estoy si(gui)endo, op. cit., pp. 33-34.

34 Cfr. ibid., p. 37. 
Me parece que aquí la única acepción de verdad defendible por parte de Derrida es la de una verdad que debe ser confesada, la verdad de la confesión del pecado original de nombrar, frente a la cual no cabría otra posibilidad de redención sino la que se hallaría en una verdad desnuda de palabra, de nombre, de logos; es decir, la verdad que con tanta dificultad nos debería dejar «ver» la mirada del gato. Por consiguiente, si el concepto de sujeto humano debe ser deconstruido deberá serlo en tanto que el sujeto del cogito cartesiano, que es tal en cuanto hombre hablante-pensante, se vería finalmente despojado de tal prerrogativa ontológica de dar nombre, y esto justo en el momento en que se ve visto desnudo por un animal, por ejemplo un gato.

\section{CONCLUSIÓN}

Según Derrida, el hombre desnudado de su humanidad ya no es capaz de contestar a la pregunta fundamental ¿yo quién soy? por sí solo, hallándola cartesianamente en la indubitabilidad de un cogito que es humano porque excluye de sí toda animalidad ${ }^{35}$. Por eso, la respuesta que Derrida le acaba dando a

35 A este respecto resultan de suma importancia las consideraciones que Derrida articula en sentido anti-cartesiano siguiendo la estela de la pregunta benthamiana sobre el sufrimiento animal («Can they suffer?»), gracias a la cual defiende la prioridad "proto-ética» de la «innegabilidad» de dicho sufrimiento por encima de la «indubitabilidad» del cogito; cfr. ibid., pp. 43-44. Para la pregunta benthamiana cfr. Bentham, J., The Collected Works of Jeremy Bentham: An Introduction to the Principles of Morals and Legislation, BuRns, J. H., HART, H. L. A. (eds.), Clarendon Press, Oxford, 1996, p. 283; trad. cast. de M. Costa, Los principios de la moral y la legislación, Ediciones Claridad, Buenos Aires, 2008, p. 291. Retomo la noción de "protoética» del trabajo de Calarco, M., "The Passion of the Animal: Derrida», en Id., Zoographies. The Question of the Animal from Heidegger to Derrida, op. cit., en part. pp. 116-121. Según este intérprete el nivel "proto-ético» de la reflexión de Derrida se manifestaría justamente en el hecho de poner en primer plano la fuerza perturbadora del sufrimiento animal que afecta el humano de modo pre-reflexivo y por ende pre-filosófico. Este planteamiento "proto-ético», por lo tanto, se ubicaría al margen del debate ético-filosófico sobre los derechos animales, ya que éste se limitaría generalmente a establecer el umbral moral de un sufrimiento consciente como condición para la atribución de estos derechos. Como es conocido, la pregunta benthamiana ha sido recuperada en el marco del debate sobre ética animal por Singer, P., Animal Liberation, Harper-Collins, New York, 2002 (1975), p. 7 (trad. cast., Liberación animal, Trotta, Madrid, 1999), y discutida posteriormente por Regan, T., The Case for Animal Rights, University of California Press, Berkeley, 1983, pp. 206-231 (trad. cast., En defensa de los derechos de los animales, Fondo de Cultura Económica, México D.F., 2017). Para una reconstrucción histórica del debate animalista cfr. Battaglia, L., Etica e animali, Liguori, Napoli, 1998. Para una perspectiva crítica sobre el antropocentrismo subyacente las clásicas posiciones defensoras de los derechos animales véase Francione, G., "El error de Bentham (y el de Singer)», en Teorema, v. XVIII, n. 3, 1999, pp. 39-60; más in extenso: Id, Rain Without Thunder: The Ideology of the Animal Rights Movement, Temple University Press, Philadelphia, 1996. Debido a los límites de este trabajo, no puedo reconstruir la relación crítica establecida por Derrida respecto al movimiento animalista. Una exposición, sino exhaustiva cuando menos indicativa, de la perspectiva derridiana se puede encontrar en DeRRIDA, J., Roudinesco, E., De quoi 
esta pregunta desemboca a su vez en la formulación de una pregunta radical que podría rezar: yo soy el animal que sigue al otro animal para preguntarle ¿yo quién soy? O, para decirlo de otro modo, el ser del hombre no podrá sino estar íntimamente ligado al seguir al animal para que le conteste a la pregunta "¿yo quién soy?»: «A menudo me pregunto, para ver, quién soy; y quién soy en el momento en que, sorprendido desnudo, en silencio, por la mirada de un animal, por ejemplo, los ojos de un gato, tengo dificultad, sí, dificultad en superar una incomodidad. ¿'Por qué esta dificultad?» ${ }^{36}$.

Para Derrida, entonces, la mirada animal en tanto que mirada de lo absolutamente otro representaría el espejo-psyche en el que el hombre no puede no mirarse si quiere hallar una respuesta a esta pregunta fundamental a la que él mismo ya no sabe qué contestar. No obstante, como señala aquí nuestro pensador, este acontecimiento no puede darse sin por ello implicar una «incomodidad»o «dificultad». Cuando Derrida articula su reflexión acerca de la experiencia inquietante del ser visto desnudo por un gato, el problema esencial al que hacer frente es que, por parte del animal, no hay una respuesta, porque no puede haber una respuesta. Es decir, el ser del yo humano se entrelaza con el seguir y el ir tras el animal para preguntarle en pos de una respuesta que este animal no puede dar, si es que se pretende que tal respuesta pertenezca al orden del discurso lógico-denominativo propio de «el Hombre».

Así, lo que se deja entrever detrás del sintagma L'animal que donc je suis es una crítica directa al corazón conceptual de la tradición antropo-teomórfica occidental y en particular a la idea cartesiana de que yo soy en cuanto ser hablante-pensante porque no soy animal, ya que el animal, siendo una máquina, no puede responder con las palabras y por ello no puede pensar ${ }^{37}$. Frente a esto Derrida parece rebatir: yo soy en cuanto sigo al animal para que me conteste a la

demain... Dialogue, Galilée, Paris, 2001, en part. pp. 105-128 (trad. cast. de V. Goldstein, Y mañana qué..., Fondo de Cultura Económica, Buenos Aires, 2009). Sobre este asunto véanse además: CalARCo, M., "Thinking through Animals: Reflections on the Ethical and Political Stakes of the Question of the Animal in Derrida», en Derridanimals, Oxford Literay Review, vol. 29, n. 1-2, 2007, pp. 1-15; Llored, P., Jacques Derrida. Politique et éthique de l'animalité, op. cit., pp. 94-106; Id., "A Philosophy of Touching Between the Human and the Animal: The Animal Ethics of Jacques Derrida», en Direk, Z., Lawlor, L. (eds.), A Companion to Derrida, Blackwell, Wiley, 2014, pp. 509-523.

36 Derrida, J., El animal que luego estoy si(gui)endo, op. cit., pp. 17-18.

37 Cfr. ibid., pp. 103-104: «no se trata únicamente de la incapacidad, para el animal, de responder a todo lo que se dice en su presencia y que puede ser una llamada, una orden, un ruido (y Descartes sabía muy bien que el animal «responde» o reacciona a ello) sino de responder a cuestiones, a preguntas, «a propósito de aquello que se les pregunta». Como si el animal pudiese en efecto responder, reaccionar a una llamada o a una orden, a la señal de su nombre por ejemplo, pero seguro que no - aunque sea mediante unas palabras mecánicamente programadas - a una pregunta. (...) El animal cartesiano (...) sería incapaz de responder a verdaderas interrogaciones. Pues carecería del poder de verdaderas preguntas. ¿Cuál es el interés de una verdadera pregunta? En esto consiste toda la cuestión, aquella que se ha podido posteriormente determinar — dicho y hecho- como cuestión del logos, de la razón, del ser o del otro». 
pregunta ¿yo quién soy? Pues bien, la no respuesta de este animal singular y real, encarnado por este gato, al interrogante "¿yo quién soy?» impide toda nueva definición de lo humano justamente porque bloquea el dispositivo conceptual que pretende compulsivamente hallar en la «esencia hablante-pensante» la respuesta a la pregunta acerca de la naturaleza humana.

En conclusión, la respuesta que nos proporcionan Derrida y el gato impide decidirse por la prioridad del ser sobre el seguir, y por ende de lo humano sobre lo animal. Como hemos querido mostrar en estas páginas, es justamente esta indecidibilidad la que nos puede proporcionar el espacio para repensar la relación humano-animal más allá del impasse teórico representado por la metafísica fonologocéntrica que desde siempre ha dividido «el Hombre» de «el Animal $»^{38}$. Dicotomía metafísica que, precisamente, halla en el cartesianismo el emblema de la concepción filosófica de la animalidad dominante en nuestra tradición ${ }^{39}$. El desafío teórico representado por estas páginas derridianas consistiría, entonces, en empujarnos a pensar à nouveau la im-posibilidad de toda relación hablante-pensante con la alteridad y, por ende, con la mismidad de un sujeto humano fundamentada en la pretensión autobiográfica de poder nombrarse a sí misma en la medida en que nombra al animal.

\section{Bibliografía}

Battaglia, L. (1998). Etica e animali. Napoli: Liguori.

Bentham, J. (2008). The Collected Works of Jeremy Bentham: An Introduction to the Principles of Morals and Legislation, Burns, J. H., Hart, H. L. A. (Eds.), Clarendon Press, Oxford, 1996; trad. cast. de M. Costa, Los principios de la moral y la legislación. Buenos Aires: Ediciones Claridad.

Bernasconi, R. (1988). "The Trace of Levinas in Derrida», en Wood, D., Bernasconi, R. (eds.), Derrida and Différance, Northwestern University Press, Evanston, pp. 13-29.

38 A este respecto, resultan de enorme relevancia las reflexiones que en este contexto Derrida desarrolla a propósito del concepto de limitrofía humano-animal, cfr. ibid., pp. 45-48. Tal limitrofía, en efecto, representaría la dimensión ontológica a partir de la cual desarrollar un nuevo marco teórico para pensar la indecidibilidad ontológica humano-animal aquí esbozada. En este sentido, la noción de limitrofía no evocaría un borde estático que separaría sus dos lados como si de un abismo ontológico entre "el Hombre» y «el Animal» se tratara, sino un espacio fronterizo que se ensancha y retroalimenta en la medida en que transforma espesando las innombrables diferencias que se entretejen entre la multiplicidad de seres vivos que habitan sus márgenes y que, justamente gracias a su pluralidad, vienen a deconstruir la unicidad metafísica de esta misma frontera. He tratado este asunto en el ya mencionado artículo «¿El cuerpo como frontera? El problema de la limitrofía ontológica humano-animal en L'animal que donc je suis de Derrida», op. cit., al que me permito aquí remitir.

39 Cfr. Grondin, J., «Derrida et la question de l'animal», en Cités, v. 2, n. 30, 2007, pp. 3139, en part. p. 33: «Dans toute la tradition philosophique, Derrida stigmatise donc un oubli de l'animal et, partant, de l'animalité même de l'homme, de cette vie qui nous traverse, mais que la philosophie s'obstine à étouffer, en l'excluant de ce qui est censé constituer le propre de l'homme». 
Brogan, W. (1989). «Plato's Pharmakon: between two repetitions», en Silverman, H. J., Derrida and Deconstruction. LondonNew York: Routledge, pp. 7-23.

Calarco, M. (2007). «Thinking through Animals: Reflections on the Ethical and Political Stakes of the Question of the Animal in Derrida», en Derridanimals, Oxford Literay Review, vol. 29, n. 1-2, pp. 1-15

Calarco, M. (2008). «The Passion of the Animal: Derrida», en Id., Zoographies. The Question of the Animal from Heidegger to Derrida. New York: Columbia University Press, pp. 103-149.

Cimatti, F. (2013). Filosofia dell'animalità. Roma-Bari: Laterza.

Critchley, S. (1999). The Ethics of Deconstruction. Derrida and Levinas. Edimburgh: Edinburgh University Press.

Culler, J. (1998). On Deconstruction, Cornell University Press, Ithaca-New York, 1982; trad. cast. de J. I. Luca de Tena, Sobre la deconstrucción. Teoría y crítica después del estructuralismo. Madrid: Cátedra.

Dalmasso, G. (1998). «Impensabilità della scrittura», estudio introductorio a la edición italiana de Derrida, J., Della grammatologia. Milano: Jaca Book (1969), pp. I-VIII.

Dalmasso, G. (2008). «Nudo im/proprio. Derrida e l'animale», en D’alessandro, P., Potestio, A. (eds.), Su Jacques Derrida. Scrittura filosofica e pratica di decostruzione. Milano: Edizioni Universitarie di Lettere Economia Diritto, pp. 197-208.

Derrida, J. (1985). La voix et le phénomène, PUF, Paris 1967, trad. cast. de F. Peñalver, La voz y el fenómeno. Valencia: Pre-Textos.

Derrida, J. (1971). De la grammatologie, Minuit, Paris, 1967, trad. cast. de O. Del Barco, C. Ceretti, De la Gramatología. México D.F.: Siglo XXI.

Derrida, J. (2007). La pharmacie de Platon, en Id., La dissémination, Seuil, Paris, 1972; trad. cast. de J. M. Arancibia, La diseminación. Madrid: Editorial Fundamentos (1975), pp. 91-260.

Derrida, J. (1977). Positions, Minuit, Paris, 1972; trad. cast. de M. Arranz, Posiciones. Valencia: Pre-Textos.

Derrida, J. (1994). "La différance», en Id., Marges - de la philosophie, Minuit, Paris, 1972; trad. cast. de C. González Marín, Márgenes de la filosofía. Madrid: Cátedra (1989), pp. 37-62.

Derrida, J. (1992). «"Il faut bien manger' ou le calcul du sujet”. Entretien avec Jean-Luc Nancy», en Id., Points de suspension. Paris: Galilée, pp. 269-301.

Derrida, J. (1999). L'animal que donc je suis (à suivre), en M.-L. Mallet (ed.), L'Animal autobiographique. Autour de Jacques Derrida. Paris: Galilée, pp. 251-301.

Derrida, J. (2006). L'animal que donc je suis, texte établi par M.-L. Mallet. Paris: Galilée; trad, cast. de C. de Peretti y C. Rodríguez Marciel, El animal que luego estoy si(gui) endo. Madrid: Trotta.

Derrida, J., Roudinesco, E. (2001) De quoi demain... Dialogue. Paris: Galilée; trad. cast. de V. Goldstein, Y mañana qué.... Buenos Aires: Fondo de Cultura Económica, 2009.

Di Martino, C. (1999). "Voce, parola, coscienza: Derrida e la genealogía», en Fenomenologia e Società, XXII, n. 2, pp. 34-74.

Ferraris, M. (2007). «Derrida e l'ontologia della scrittura», en Id., Differenze. La filosofía francese dopo lo strutturalismo. Milano: Albo Versorio, pp. 33-70.

Finas, L. (1973). «Indecidibles», en Vv.Aa., Écarts : quatre essais à propos de Jacques Derrida. Paris: Fayard, pp. 321-322.

Firenze, A. (2017). «"A dog does not exist but merely lives”: The Question of Animality in Heidegger's Philosophy», en Philosophy Today, v. 61, n. 1, pp. 135-154. 
Firenze, A., «¿El cuerpo como frontera? El problema de la limitrofía ontológica humano-animal en L'animal que donc je suis de Derrida», en Philosophical Readings. Online Journal of Philosophy (artículo aceptado, pendiente de publicación).

Fontenay, E. De (1998). Le silence des bêtes. La philosophie à l'épreuve de l'animalité. Paris: Fayard.

Francione, G. (1999). El error de Bentham (y el de Singer), en Teorema, v. XVIII, n. 3, pp. 39-60.

Francione, G. (1996). Rain Without Thunder: The Ideology of the Animal Rights Movement. Philadelphia: Temple University Press.

Grondin, J. (2007). «Derrida et la question de l'animal», en Cités, v. 2, n. 30, pp. 31-39.

Heidegger, M. (1983). Die Grundbegriffe der Metaphysik. Welt - Endlichkeit - Einsamkeit. Frankfurt a.M.: Vittorio Klostermann Verlag; trad. cast. de A. Ciria, Los conceptos fundamentales de la metafísica. Mundo - finitud - soledad. Madrid: Alianza, 2007.

Lawlor, L. (2007). This Is Not Sufficient. An Essay on Animality and Human Nature in Derrida. New York: Columbia University Press.

Llored, P. (2013). Jacques Derrida. Politique et éthique de l'animalité. Paris: Éditions Sils Maria.

Llored, P. (2014). «A Philosophy of Touching Between the Human and the Animal: The Animal Ethics of Jacques Derrida», en Direk, Z., Lawlor, L. (eds.), A Companion to Derrida. Wiley: Blackwell, pp. 509-523.

Norris, C. (2002). Deconstruction: Theory and Practice. London-New York: Routledge (1982).

Pelgreffi, I. (2013). "Animale autobiografico. Derrida e la scrittura dell'autos», en Lo Sguardo. Rivista di Filosofia, n. 11, (I), pp. 229-298.

Pelgreffi, I. (2015). La scrittura dell'autos. Derrida e l'autobiografia. Giulianova: Galaad Edizioni.

Peretti, C. De (1989). Jacques Derrida. Texto y deconstrucción. Barcelona: Anthropos.

Petrosino, S. (1983). Jacques Derrida e la legge del possibile. Napoli: Guida.

Petrosino, S. (2015). "Ancora su il pharmakon di Derrida», en Derrida, J., La farmacia di Platone. Milano: Jaca Book (1985), pp. 7-47.

Petrosino, S. (2010). La scena umana. Grazie a Derrida e Lévinas. Milano: Jaca Book.

Platón (1986). Fedro, en Diálogos, v. III, Fedón, Banquete, Fedro, traducciones, introducciones y notas de C. García Gual, M. Martínez Hernández, E. Lledó Íñigo. Madrid: Gredos.

Platón (1981). Apología, en Diálogos, v. I, Apología, Critón, Eutifrón, Ion, Lisis, Cármides, Hípias Menor, Hipias Mayor, Laques, Protágoras, Introducción general de E. Lledó Íñigo, traducción y notas de J. Calonge Ruiz, E. Lledó Íñigo, C. García Gual. Madrid: Gredos.

Platón (1988). República, en Diálogos, v. IV, República, Introducción, traducción y notas de C. Eggers Lan. Madrid: Gredos.

Ramond, C. (2001). Vocabulaire de Derrida. Paris: Ellipses.

Regan, T. (1983). The Case for Animal Rights. Berkeley: University of California Press; trad. cast., En defensa de los derechos de los animales, Fondo de Cultura Económica, México D.F., 2017.

Singer, P. (1999). Animal Liberation, Harper-Collins, New York, 2002 (1975); trad. cast., Liberación animal. Madrid: Trotta,.

Szlezák, T. A. (2001). "L'idée du Bien en tant qu'archê dans la "République" de Platon», en Fattal, M. (ed.), La philosophie de Platon. Paris: L’Harmattan, pp. 345-372. 
Trabattoni, F. (1994). Scrivere nell'anima. Verità, persuasione e dialettica in Platone. Firenze: La Nuova Italia.

Vegetti, M. (1989). «Nell'ombra di Theut. Dinamiche della scrittura in Platone», en Detienne, M. (ed.), Sapere e scrittura in Grecia. Roma-Bari: Laterza, pp. 201-227.

Vegetti,, M. (1993). «L'idea del bene nella "Repubblica” di Platone», en Discipline filosofiche, n. 1, pp. 207-229.

Vergani, M. (2000). Derrida. Milano: Mondadori.

Vergani, M. (2002). Dell'aporia. Saggio su Derrida. Padova: Il Poligrafo.

Wood, D., Bernasconi, R. (eds.) (1988). Derrida and Différance. Evanston: Northwestern University Press.

Wyschogrod, E. (1989). «Derrida, Levinas and violence», en Silverman, H. J. (ed.), Derrida and Deconstruction. London-New York: Routledge, pp. 177-194.

Universitat Pompeu Fabra, Barcelona

Antonino FirenZe

Departamento de Humanidades

antonino.firenze@upf.edu

[Artículo aprobado para publicación en febrero de 2020] 